\title{
Coordinated Optimization: Marine Oil Spill Emergency Management in China
}

\author{
ZHAO, Ling \\ College of Marine Culture and Law, Shanghai Ocean University \\ l-zhao@shou.edu.cn
}

Publication Information:

Received 31 August 2018, Accepted 29 November June 2018, Available online 31 December 2018

doi: 10.21463/jmic.2018.07.2.10

\begin{abstract}
Marine environmental emergency management is featured with multiple participants and complex interactions between and among various sectors. It needs a coordinated mechanism to settle the complicated cooperation and allocation of personnel and resources in an effective and efficient way. In China, the government emergency response system runs according to the classification of types, levels and stages for the emergency issues. The main players of the system relevant to marine environmental issues consist of relevant regional and local government sectors of different levels, national government sectors including State Oceanic Administration, Maritime Safety Administration, Ministry of Environmental Protection, etc. private sectors and civil society. The efficiency and effectiveness of the response system has been a challenge in this area. This paper comprehensively analyzes status quo of the coordinated system in the response management in China. Based on it, the policy recommendations with more coordination and better responsiveness has been put forward to improve the relevant regulations, the participating mechanism and regional and local collaboration mechanism.
\end{abstract}

\section{Keywords}

marine environment, oil spills, emergency management, emergency response, collaboration, coordinated management, China 


\section{Introduction}

Offshore oil spill accidents are one of the frequently occurred marine environmental emergencies due to the large demands of crude oil in China in recent years. As the oil pollution spreads fast and stays durative, the delayed and unprofessional response can very likely cause long-term adverse effects on ocean environments. In the past few years, marine oil spill accidents like "7.16" accident in Dalian in 2010, 19-3 oil spill in Penglai in 2011, East Yellow oil pipeline explosion accidents in Qingdao Island in 2013 and the sinking of the oil tanker Sanchi in the East China Sea in 2018 have aroused wide public concern and the consciousness of Chinese governments of all levels to improve the oil spill emergency management. Oil spill response involves many interest groups including public sectors of different levels and types, petrol producers and professional relief enterprises, marine environmental non-governmental organizations, fishermen and citizens in coastal cities. Therefore, coordination and cooperation of each related part is key to its emergency management, which requires coordinated operation of people, resources and technology (Jiang, et al., 2014). What public emergency managers are considering is how to effectively and efficiently distribute the personnel and the equipment to the most needed places, how to get the capital and the technology in a fair way during the collaboration. They need to deal with at least three issues related to collaboration and coordination: who is able to lead and organize the coordination system? Where are the resources and personnel? How to coordinate them? In this paper, we discuss the coordination structure, emergency resource distribution and personnel coordination mechanism that China has achieved till now. Specifically, how the oil spill response coordination structure comprise leaders and participants in China are discussed. In the resource distribution system, the emergency resources and its operational mechanism are showcased, and then how the resources are distributed coordinately is demonstrated. After the discussion, the existing problems and difficulties in the current coordination work are gone through in detail. Finally, the policy recommendations have been put forward that the system needs further optimizing: operationalization of law and regulation, multiple participating mechanism and regional and local collaboration mechanism that can help response emergency timely and effectively by allocating resources and personnel across different sectors.

\section{The current oil spill emergency coordination system in China}

\subsection{The framework of the emergency response system for major marine oil spill accidents}

Chen and $\mathrm{Wu}$ (2014) have shown that coordination issues of major oil spill emergency management in China has long been put attention to by the authority. In the research of Zhu's (2012), late information release, lack of quick and efficient emergency measures, and unclear responsibility are three dominating problems that the public complained in the Penglai 19-3 oil spill events. Chen and Liu (2011) pointed out State Oceanic Administration, as an offshore oil platform emergency authority, "deals with the problem in a soft attitude" in the Penglai-3 accident made the public angry and disappointed. As discussed (Chen and Wu, 2014; He, Gu and Li, 2013), one of the root causes of these problems is that State Oceanic Administration's rank is not high enough to mobilize the relief resources that is under other departments' charge. 
The marine oil spill accidents are mainly classified into four types in China according to their producing process: accidents caused by the offshore oil \& gas platform production, marine oil carrier, oil storage and oil pipeline, etc., and this classification is based on the production places that oil spills occur and their geographic locations. Due to the functional specialization, the marine oil spill emergency management in China is undertaken by different departments. Specifically, National Oceanic Administration mainly focuses on oil spill monitoring and surveillance providing oil spill information but is not able to carry out the response by itself due to lack of relief equipment and vessels. When accidents occur, the Administration has to ask other departments or sectors, for instance, Maritime Safety Administration, or oil production enterprises to provide relief equipment and vessels. It has been discussed a lot that the horizontal cooperation at the same level has always been difficult in a bureaucratic system. Bureaucratic hierarchical control has a characteristic of impersonalization, so in the face of the instructions not from the higher authority, even with the rationality and necessity, the relevant departments would very possibly refuse to enforce or feign to perform. So when the commander of the system is not clear, the rescue response cannot be carried out smoothly. Therefore, the China's central government found it necessary to establish an oil-spill emergency management coordination system at the national level to deal with the major problem.

After the Dalian "7.16" accident, the Office of Committee on Organizational Structure of the CPC Central Committee issued "a notice of the leading sector and the division of duties of major oil spill emergency management", which clearly made demands on Ministry of Transport to compile a marine oil spill emergency capability planning with other relevant national departments and organizations to coordinate the emergency management work (Hainan Maritime of Safety Administration of the People's Republic of China, 2017). Then the National Major Offshore Oil Spill Response Capacity Building Plan (2015-2020) was compiled and this endeavor helped to establish a framework of the offshore oil spill response work and the Ministry of Transport also began to shoulder a leading role in the work.

Another important step to improve the marine oil spill emergency management system was the establishment of "Marine Oil Spill Response Center of China" based on the original "Marine Transportation Safety and Relief Center" affiliated to the Ministry of Transport to strengthen the professional management in this area, which improved the integration and coordination of the classified management of oil spills in the various departments in the past six years in a certain degree. In addition, in 2012 a coordination mechanism-the Joint Inter-ministerial Meeting of the National Marine Oil Spill Emergency Management-was established on the basis of the National Maritime Search and Rescue Meeting under the supervision of Ministry of Transport.

The combination of the above mentioned two systems now has become a major oil spill emergency coordinating body on the national level in China. The following table demonstrates the members of the agencies and their responsibilities in the management of the oil spill emergency: 
Table 1. The Major Oil Spill Response Coordination System in China

\begin{tabular}{|c|c|c|}
\hline Agency & Members or Affiliation & $\begin{array}{c}\text { Duties and Responsibilities in Marine Oil Spill Emergency } \\
\text { Management }\end{array}$ \\
\hline $\begin{array}{l}\text { Marine Oill Spill Response } \\
\text { Center of China }\end{array}$ & $\begin{array}{l}\text { Co-handling affairs with Emergency Office of Ministry of } \\
\text { Transport }\end{array}$ & $\begin{array}{l}\text { The Center is responsible for the following work: } \\
\text { - daily work of the Joint Inter-ministerial Meeting of } \\
\text { the National Marine Spill Emergency Management; } \\
\text { - organizing, coordinating and commanding the } \\
\text { major accidents of oil spills from vessels and } \\
\text { barrier clearance in navigable waters; and } \\
\text { - compiling major national marine oil spill } \\
\text { emergency planning and implementing, } \\
\text { coordinating and commanding the national marine } \\
\text { oil spill emergency response. }\end{array}$ \\
\hline $\begin{array}{l}\text { The Joint Inter-ministerial } \\
\text { Meeting of the National } \\
\text { Marine Oil Spill Emergency } \\
\text { Management }\end{array}$ & $\begin{array}{l}\text { Emergency Office of the State Council, Ministry of Foreign } \\
\text { Affairs, National Development and Reform Commission, } \\
\text { Ministry of Industry and Information Technology, Ministry of } \\
\text { Transport, Ministry of Public Security, Ministry of } \\
\text { Environmental Protection, Ministry of Agriculture, Ministry } \\
\text { of Health, General Administration of Customs, Civil Aviation } \\
\text { Administration, State Administration of Work Safety, } \\
\text { National Energy Administration, China Meteorological } \\
\text { Administration, State Oceanic Administration, the } \\
\text { Headquarters of General Staff of the PLA, the Navy, the } \\
\text { Airforce, the Armed Police, China National Petroleum } \\
\text { Corporation, China Petroleum \& Chemical Corporation, } \\
\text { China National Offshore Oil Corporation, China COSCO } \\
\text { Shipping Corporation Ltd, etc. (Bei, 2013). }\end{array}$ & $\begin{array}{l}\text { Under the leadership of the State Council, the Meeting is } \\
\text { responsible for the following work: } \\
\text { - solving the major issues of marine oil spills and } \\
\text { providing related policy suggestions; } \\
\text { - studying and examining the National Major Oil Spill } \\
\text { Emergency Management Plan; } \\
\text { - studying the national planning of the major marine } \\
\text { oil spill response capability; } \\
\text { - organizing, coordinating and commanding the } \\
\text { major oil spill response operation; } \\
\text { - evaluating the response of the major oil spills; and } \\
\text { - directing, supervising the marine oil spill response } \\
\text { management of the coastal local governments and } \\
\text { the relevant enterprises (Liu, 2013). }\end{array}$ \\
\hline
\end{tabular}

The establishment of this command coordination system has preliminarily resolved the problem of the division of the oil spill emergency management at the national level and the inability to mobilize the resources horizontally because of the low level of the command departments. After reshaping, the institutions and components of China's major oil spill response command system are shown below:

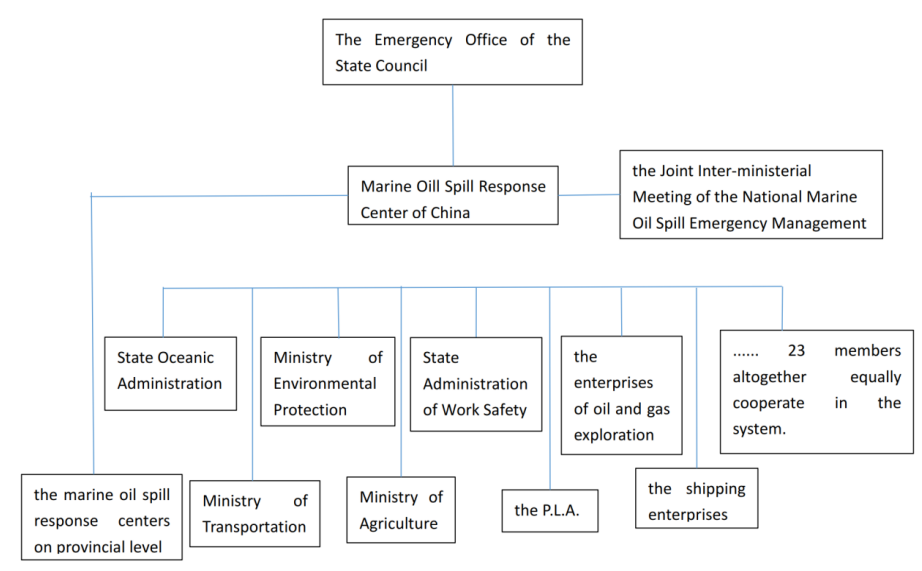

Fig 1. China's Major Oil Spill Response Command System. Note: In 2018, Ministry of Environmental Protection has been reconstructed and renamed as Ministry of Ecology and Environment. Meanwhile, State Administration of Work Safety has been merged into Ministry of Emergency Management. 


\subsection{The emergency resource allocation system}

The allocation of emergency resources requires institutional, procedural and financial guarantee. Firstly, in terms of the resource coordination system, the existing laws and regulations in China has put forward some basic principles. According to the Regulations on the Prevention and Control of Vessel Pollution to the Marine Environment, the coastal port enterprises should prepare and store a large number of oil spill accident response devices including oil boom, oil collection machines, oil absorption materials, dispersant, wastes cleaning vessels, emergency facilities and storage tankers. In addition, according to the 2007 planning of the national offshore transportation safety and relief system and the national crude oil transportation networks and sensitive area resources distribution, till the year of 2020 , the coastal governments of all levels will help to construct 16 marine oil spill emergency equipment warehouses, which will strengthen the integration and coordination ability to allocate resources.

Secondly, the resource system comprises three elements: oil spill surveillance and monitoring system, emergency disposal equipment system, and emergency response team. In China, the governmental functions of marine environmental emergency management is mainly played by various departments or ministries including State Oceanic Administration, Maritime Safety Administration, Ministry of Ecology and Environment of the People's Republic of China (newly established based on Ministry of Environmental Protection), Bureau of Fisheries, the navy of P.L.A., etc. The management is carried out in accordance with the pollution happening in different locations. Based on this principle, the onshore environmental issues are mainly governed by Ministry of Ecology and Environment and the offshore environmental issues shall be the responsibility of State Oceanic Administration while the pollution caused by marine vessels shall be dealt with by Maritime Safety Administration. Bureau of Fisheries is responsible for the fishing vessel pollution and the Navy responds to the pollution caused by warships respectively. Correspondingly, these different departments are also responsible for the relevant emergency management of marine oil spills. Besides public sectors, the interest parties also consist of relevant oil production and transportation enterprises that should be the first responsible actors of oil spill accidents.

Thirdly, to guarantee the fund supply, China is trying to establish a better compensation mechanism for emergency resource requisition among different sectors. In May 2012, the Measures for the Use and Management of Marine Oil Pollution Damage Compensation Fund were issued. In terms of the article 17, "the emergency disposal expenses to reduce the oil pollution damage will be compensated first before any others by the fund" (the State Council, 2012). The Measures for the Civil Liability Insurance for Oil Pollution Damage issued in August 2013 stipulate, "all oil tankers and other types of vessels of over 1,000 gross tonnage shall effect relevant insurance. All oil tankers and other types of vessels of over 10,000 gross tonnage shall sign agreements beforehand with the professional oil disposal enterprises to remove pollution in the events of oil spills"(the State Council, 2012). All these measures are helpful to ensure emergency funding in a certain degree.

\subsection{The emergency information and personnel coordination mechanism}

Besides resources, another very important factor that affect the effectiveness of offshore oil spill response is information sharing and personnel collaboration. To establish a coordination system in the field, Chinese government try to focusing on the following work to improve the information and personnel collaboration systems. 


\section{Establishing an oil spill emergency information system}

Marine Oil Spill Response Center of China carried the responsibility to build an oil spill emergency information sharing system. The system comprises emergency communication system and the emergency information service system based on the wired, wireless public network and private network which can improve the maritime search and rescue emergency communication network. The Joint Inter-ministerial Meeting of the National Marine Spill Emergency Management also strengthens the information communication of the special network among the relevant sectors including public departments, private enterprises and social organizations to ensure the real-time voice, data exchanges and video communications in the accidents.

In addition, the National Major Offshore Oil Spill Emergency Capacity Building Plan declared from 2015 to 2020, based on the existing information system and database of the relevant departments, China will build an oil spill emergency information service system to connect Marine Oil Spill Response Center of China, provincial marine oil spill emergency centers and other major members of the Joint Inter-ministerial Meeting of the National Marine Spill Emergency Management to realize a real time oil spill information sharing (Ministry of Transport of the People's Republic of China, 2016).

\section{(2) Organizing regular joint exercises}

Another key point in coordinating the rescue efforts is the cooperation among different rescue teams and workers. To enhance the ability of collaboration, The Joint Inter-ministerial Meeting of the National Marine Spill Emergency Management requires the relevant departments and units to conduct at least one major offshore oil spill response exercise each year. The drills carrying out between and among the various organizations offer good opportunities for the relative emergency personnel who participate in to enhance their ability to collaborate during the accidents. Through the exercises, they can not only improve actual operational ability in practice but also help them deal with the rescue scene professionally.

\section{The existing problems in the current coordination system}

Although measures and methods have been taken to reinforce the offshore oil spill response ability and coordination as what have been mentioned above, still some factors act as a drag in the work. The following will probe into three important issues that have drawn attentions.

\subsection{The regulation issues}

Laws and regulations are the basis for the orderly emergency management. However, there are still many problems in the relevant laws and regulations concerning the emergency coordination and management of oil spills. The main problem is the lack of coordination and operability among the different relative laws and regulations. For example, the Marine Environmental Protection Law only stipulates that the responsible party has the obligation to inform and report after the oil spills, but no operational provisions have been made on which sectors or departments should be notified after the accidents. While the Environmental Emergency Plan states that the relative environmental protection 
departments should be responsible for the guidance and coordination on major emergency environmental accidents, but in the real situation, the main responsibility of oil spill response is carried by Maritime Safety Administration and State Oceanic Administration. In addition, some coastal regional and local governments have not compiled oil spill emergency response plans, which makes it hard for the relative local governments and the competent departments to carry out the coordination according to the law.

\subsection{The resource allocation issues}

As the discussion above, China has some mechanisms of resource allocation, but the efficient and effective resource deployment still needs scrutinizing and improving. The existing problems are the resource allocation in China is relatively fragmented and some purchasers, managers and users of the resources are not in the same sectors which wastes funds and builds redundant projects. At present, the emergency of oil spill rescue capability and resources in China are scattered in different sectors. Take some major players of oil spill response departments as an example:

1. Ministry of Environmental Protection: onshore oil spill monitoring system, equipment and rescue forces;

2. State Oceanic Administration: offshore oil monitoring system, especially offshore oil platforms and oil pipeline monitoring;

3. State Maritime Safety Administration: oil spill relief vessels and disposal equipment;

4. other government departments including Bureau of Fisheries: rescue personnel and equipment;

5. military force: the Navy, the Air Force: monitoring and rescue equipment;

6. port enterprises: radar surveillance and monitoring system, emergency rescue personnel and equipment;

7. oil and gas exploration enterprises: oil spill monitoring and alarm system and disposal equipment;

8. ship transport enterprises: oil spill monitoring and alarm system on ships, rescue equipment and forces;

9. oil and gas storage and transport enterprises: oil spill monitoring and rescue equipment of oil pipeline and storage;

10. professional enterprises of oil spill disposal: professional equipment and team;

11. the volunteer team for the emergency clearance of oil spill organized by local governments.

In actual oil spill response work, each department has its own professions and resources. For instance, State Maritime Safety Administration under Ministry of Transport has a stronger operational capability and State Oceanic Administration enjoys a strong surveillance monitoring ability while Ministry of Environmental Protection can deal with onshore emergencies better. How to cooperate and coordinate smoothly among departments requires more work among the different sectors.

\subsection{The trans-regional and local collaboration issues}

The core fundamental principle of China's emergency management system is "classified management, hierarchical responsibility, and dependency administration"(The State Council, 2007). When the oil spill accident failed to reach the level of major accidents, according to China's emergency management plan system, it would become the duty of the related emergency rescue organization on the regional or local level. Due to the oil diffuse and flow, oil spill emergency response often involves the cross-regional teams, and also needs horizontal and vertical coordination among departments on different governmental levels. However, at present there is still a lack of agreements between and 
among different regional and local departments, which makes it difficult to have rescue cooperation on the relevant levels.

\section{Coordination system optimization recommendations}

From the perspective of the existing rescue process, the process design involves the normalization and institutionalization of the coordination, so that the participating departments can have a clearer role and operational process to ensure the efficiency of the emergency disposal. From the discussions above, it is a necessity that the relevant laws and regulations are the basis for the action taken by different parties. Also the participating mechanism needs a decision-making design and resource allocation process design. Moreover, the regional and local collaboration mechanism is an important guarantee for the long-term stability of the cooperation in all levels. So the policy should focus on the three changes as follows.

\subsection{Improving the coordination of the relative laws and regulations}

The improvement of the major oil spill disposal system requires a series of optimization and improvements, and the law and regulation improvement is one of the key factors that need putting efforts on. The auxiliary system needs to be more practical in the design of oil spill emergency. For example, the relationship between the Oil Spill Emergency Center and other members requires more clarification. In the relevant laws, the reporting procedure after the accident, the information sharing and the rescue responsibility identification have not been clarified and identified clearly to avoid the confusing situation when accidents happen. Besides, the laws and regulations shall pay special attention to reduce the level of control, realize the rapid scheduling of cross-regional and inter-departmental resources including oil removing equipment, response teams, surveillance equipment, transport resources, medical assistance resources, emergency protection, communication and information systems in the coordination process design.

\subsection{Designing multi-body participating mechanisms}

Great importance should be attached to the process of public participation and expert consultation, which can involve the professional rescue departments and the interests parties in the rescue system. The experts and involving teams can contribute to the risk assessments and legitimacy together leading to a more scientific and reasonable emergency rescue on the various phases of the oil spills.

As we have discussed, another key difficulty of the disaster emergency coordination mechanism lies in how to share expenses and determine who should be responsible for the payment including the fees of emergency facilities, equipment procurement, operations, maintenance and update, personnel training, emergency drills, etc. Although some measures have been scrutinized above, much can be done in the future. First, special funds should be set up in this fields. Oil spill emergency resource coordination involves different owners and sectors of different scales. If a smooth response process needs to be achieved, they should reach an agreement on their responsibility, obligation and interests, which requires a mechanism to compensate for the losses in the rescue of different sectors. Besides, the relevant 
enterprises should effect the insurance of environmental liability and set up the trust funds together with the efforts of the central government and coastal local governments. Also, the joint contributing mechanism of resource warehouses can be another tool. Besides, oil spill emergency supplies usually require a large amount of reserves and regular replacement, leading to a high pressure on enterprises. To solve these problems, on the one hand, we must strengthen the supervision and administration of the public sectors, and on the other hand, the relevant private enterprises and departments should share the duty and jointly build emergency supply warehouses. The government shall also encourage the regional alliance or associations to invest on the warehouses.

\subsection{Improving the regional and local-level coordination system}

The major marine oil spill emergency management coordination mechanism discussed above is aimed to fortify the strength at national level. However, how to carry out regional emergency coordination still needs further exploration. The regional level is on a smaller scale but still involves trans-regional, cross-sector resource scheduling. The integration of regional resources can be realized from three aspects as follows.

Firstly, the institutional foundation is very important. The related legislation can protect and ensure that the cooperation is based on mutual benefits and is carried out with equal rights and duties. Secondly, resource distribution information system shall also be established on the regional and local level as the national level. We can build up resource distribution maps and archives to accurately elaborate resource locations, show the relevant subordinate departments, and make the resource schedule in a reliable way. Thirdly, resource command system similar to the national level should be established to quickly coordinate the distribution of resources and personnel in the relevant departments on the provisional and local level. For instance, the oil spill emergency command headquarters led by the various local maritime administrations and the Maritime Search and Rescue Centers at all levels can be established and act as a leading role in the provincial and local response systems as the Marine Oil Spill Response Center of China on the national level.

\section{Conclusion}

After the reflection and summary of the accidents recently, China has improved the major offshore oil spill emergency response system and also achieved an initial success on resource and personnel allocation mechanism but still needs to upgrade the coordination mechanism in law and regulation design, multiple participating cooperation system and regional and local collaboration mechanism as to improve the efficiency and effectiveness of the offshore oil spill emergency management nationwide. 


\section{References}

Bei, S. J., 2013. China's major maritime oil spill response capacity has been significantly improved - the first national joint meeting on emergency management of major offshore oil spills took place. China Maritime Safety. 01:61-62.

Chen, A., \& Liu, X., 2011. The Penglai 19-3 oil spill accident and emergency management review. Science and Technology for Development. $7: 23$ to 28 .

Chen, T. \& Wu, L., 2014. Study on the "problematic" mechanism of oil spill in penglai 19-3 - from the perspective of constructivism. Journal of Nanjing Forestry University (Humanities and Social Sciences Edition). v14n2:52-60.

Chen, T., \& Wu, L.,2014. The problematic mechanism research of Penglai 19-3 Oil Spill Incident, based on the constructivism perspective. Journal of Nanjing Forestry University (Humanities and Social Science Edition). v14n2:52-60, 10.

Hainan Maritime of Safety Administration of the People's Republic of China, 2017. Notice of Carrying out National Major Offshore Oil Spill Response Capacity Building Plan (2015-2020). Hainan Maritime of Safety Administration of the People's Republic of China: http://www.hnmsa.gov.cn/hsfw_5_1/20170310/29904.html - accessed March 10, 2018.

He, S., Gu F. \& Li J.P., 2013. Emergency command in China's international oil cooperation - taking the oil spill in Bohai Bay as an example. Ecological Economy (Academic Edition). 2:333-376.

Jiang Y., Chen, X., Chao, W., etc., 2014. The key problem of China's major marine oil spill emergency resource allocation mechanism. China Water Transport. 8:24-25.

Liu Y., 2013. The effectiveness of the Inter-ministerial joint meeting system remains observing. China Energy News (the 14th edition): http://paper.people.com.cn/zgnyb/html/2013-07/01/content_1262092.htm - accessed July 1, 2018.

Ministry of Transport of the People's Republic of China, 2016. The National Major Offshore Oil Spill Emergency Capacity Building Plan offers a top-level design to the establishment of offshore oil response capability. Ministry of Transport of the People's Republic of China: http://www.mot.gov.cn/zxft2016/jianshegh/ - accessed May 28, 2018.

The State Council, 2007. The National Act of Emergency Response (article 4). The State Council, the People's Republic of China: http://www.gov.cn/flfg/2007-08/30/content_732593.htm - accessed June. 30, 2018.

The State Council, 2012. The Measures for the Use and Management of Marine Oil Pollution Damage Compensation Fund. The State Council, the People's Republic of China: http://www.gov.cn/zwgk/2012-05/28/content_2147033.htm - accessed May 28, 2018.

The State Council, 2012. The Measures for the Civil liability Insurance for Oil Pollution Damage (2010). The State Council, the People's Republic of China: http://www.gov.cn/flfg/2010-09/26/content_1709983.htm - accessed July 1, 2018.

Zhu, Q.,2012. The review on government information release system oil of spill emergency in Penglai 19-3 oil spill events. Journal of China University of Geo-sciences (Social Sciences Edition. v12n3:32-39 + 139. 